\title{
Identification of subgroups of metastatic castrate-resistant prostate cancer (mCRPC) patients treated with abiraterone plus prednisone at low vs. high risk of radiographic progression: An analysis of COU-AA-302
}

Lisa J. Martin, MD; Shabbir M.H. Alibhai, MD²; Maria Komisarenko, MD ${ }^{1}$; Narhari Timilshina, $\mathrm{MD}^{2}$; Antonio Finelli, $\mathrm{MD}^{1}$

${ }^{1}$ Princess Margaret Cancer Centre, University Health Network, Toronto, ON, Canada; ${ }^{2}$ Toronto General Research Institute, University Health Network, Toronto, ON, Canada

Acknowledgements: This study, carried out under YODA Project \#2016-1122 (http://yoda.yale.edu/datarequest/2016-1122), used data obtained from the Yale University Open Data Access Project, which has an agreement with Janssen Research \& Development, L.L.C. The interpretation and reporting of research using these data are solely the responsibility of the authors and does not necessarily represent the official views of the Yale University Open Data Access Project or Janssen Research \& Development, L.L.C.

Cite as: Can Urol Assoc J 2018 November 5; Epub ahead of print. http://dx.doi.org/10.5489/cuaj.5586

Published online November 5, 2018

$* * *$

\section{Abstract}

Introduction: Radiographic imaging is used to monitor disease progression for men with metastatic castrate-resistant prostate cancer (mCRPC). The optimal frequency of imaging, a costly and limited resource, is not known. Our objective was to identify predictors of radiographic progression to inform the frequency of imaging for men with mCRPC. Methods: We accessed data for men with chemotherapy-naive mCRPC in the abiraterone acetate plus prednisone (AA-P) group of a randomized trial (COU-AA-302) (n=546). We used Cox proportional hazards modelling to identify predictors of time to progression. We divided patients into groups based on the most important predictors and estimated the probability of radiographic progression-free survival (RPFS) at six and 12 months.

Results: Baseline disease and change in prostate-specific antigen (PSA) at eight weeks were the strongest determinants of RPFS. The probability of RPFS for men with bone only disease and a $\geq 50 \%$ fall in PSA was 93\% (95\% confidence interval [CI] 87-96) at six months and 80\% (95\% CI 72-86) at 12 months. In contrast, the probability of RPFS for men with bone and soft metastasis and <50\% fall in PSA was 55\% (95\% CI 41-67) at six months and 34\% (95\% CI $22-$ 47) at 12 months. These findings should be externally validated. 
Conclusions: Patients with chemotherapy-naive mCRPC treated with first-line AA-P can be divided into groups with significantly different risks of radiographic progression based on a few clinically available variables, suggesting that imaging schedules could be individualized.

\section{Introduction}

Healthcare spending for cancer imaging has increased faster than that for overall cancer care. ${ }^{1}$ This increase includes imaging after diagnosis of advanced cancer. ${ }^{2,3}$ More frequent imaging in advanced cancer may detect disease progression earlier and lead to changes in treatment; however, it may also have negative effects such as increased anxiety and more time spent in medical facilities. ${ }^{4}$

Despite early detection and aggressive treatment of early prostate cancer, some men will develop metastatic disease, with about $90 \%$ of them developing bone metastases. The recent development of new treatment options (for example, abiraterone acetate and enzalutamide) for men with metastatic castrate-resistant prostate cancer (mCRPC) may increase the importance of monitoring for disease progression; however, the optimal imaging schedule for mCRPC patients is not known.

Given that imaging is an expensive and limited resource, it would be beneficial if the imaging schedule could be risk-adapted for likelihood of disease progression. In this study, we examined factors associated with radiographic progression in mCRPC patients treated with abiraterone acetate plus prednisone (AA-P), and explored the possibility that a few clinically available variables could be used to identify subsets of patients with different risks of developing radiographic progression.

\section{Methods}

\section{Data source}

We accessed data from participants in the AA-P group $(n=546)$ of COU-AA-302, a randomized Phase III trial of AA-P treatment prior to chemotherapy for mCRPC patients ${ }^{5}$, through the Yale University Open Data Access Project. The clinical cut-off date was March 31, 2014. Details of the trial eligibility criteria and methods are described elsewhere. ${ }^{5}$ Patients with visceral metastases at baseline were excluded. The study protocol included bone scans and computed tomography or magnetic resonance imaging at baseline, every 8 weeks during the first 24 weeks, and every 12 weeks thereafter. Unscheduled scans were performed as determined by treating physicians.

\section{Data analysis}

We approached the data analysis in two ways: (i) we developed a multivariable prognostic model for radiographic progression using Cox Proportional Hazards $(\mathrm{PH})$ modelling and calculated a 
risk score; and (ii) we identified the two variables most predictive of progression and used them to stratify patients into subsets.

The outcome measure was time from randomization to radiographic progression in bone and/or soft tissue based on the investigator assessment of progression. As previously described ${ }^{5}$, bone progression was defined as the appearance of at least 2 new lesions and required confirmation on a subsequent scan with 6 weeks. For lesions detected $<12$ weeks after randomization, confirmation required the presence of 2 additional lesions, and for those detected $\geq 12$ weeks after randomization, confirmation required the continued presence of 2 lesions. We assigned the time of bone progression as the date of the scan prior to the confirmatory scan. Progression in soft tissue disease was determined by CT or MR imaging based on the modified RECIST. ${ }^{6}$ Patients who discontinued treatment or died before experiencing radiographic progression were censored at their last scan.

\section{Baseline variables}

We considered the following baseline variables: age, body mass index, ECOG performance status, extent of baseline disease (bone, soft or both), Gleason score, prior radiation therapy or prostatectomy, presence of pain (BPI-SF item 3), and serum levels of prostate specific antigen (PSA), lactate dehydrogenase (LDH), albumin, alkaline phosphatase (ALP) and hemoglobin. We included a missing category for Gleason Score (11\% missing) and excluded 35 patients (6\%) who were missing data for other baseline variables. PSA and ALP were log transformed as their distributions were highly skewed. All baseline variables were included in a Cox PH model and a manual backward selection process was used to remove covariates that were not statistically significant $(P>0.05)$ and whose exclusion had little effect (change $<0.01)$ on the concordance statistic (C-statistic) ${ }^{7}$ for the model.

\section{Change variables}

We calculated the percent change in laboratory variables from baseline to week 8 (the first time PSA was measured). After excluding subjects with missing data for change variables (7\% of patients with complete baseline data), the final sample included 470 subjects with 265 events (86\% of the total sample of 546). All change variables (continuous) were added to the baseline model and change variables with $\mathrm{p}>0.05$ and little effect on C-statistic were removed. We dichotomized change in PSA and ALP for the final model. For PSA we used 50\% decline as the cut-point because it is close to the observed median change in PSA. The cut-point of a 20\% increase for ALP was based on the observed shape of the association with progression.

The validity of the PH assumption was checked by plotting the cumulative score residuals against time and by the Kolmogorov-type supremum test.

\section{Risk score}

We calculated risk scores for subjects by multiplying their covariate values by the appropriate regression coefficient from the final multivariable model. We estimated the probability of 
radiographic progression free survival (RPFS) at 6 and 12 months within each tertile of risk score from the Kaplan-Meier estimates.

Stratified analysis

We used best subset regression to identify the best model (based on model ranking by score and C-statistic) with a maximum of 2 variables to predict radiographic progression and divided the subjects into risk strata based on these variables. We estimated the probability of RPFS at 6 and 12 months within each stratum based on the Kaplan-Meier estimates.

We stratified subjects on the variables most strongly associated with bone progression only because bone progression may be more clinically relevant in terms of symptoms experienced. Furthermore, in this study population progression in soft tissue largely represented growth in lymph node lesions for which the clinical significance may be limited.

Statistical analyses were performed using SAS Drug Development 9.3 and the survival package in R 2.14.0. The study was approved by the University Health Network Research Ethics Board.

\section{Results}

The distribution of variables is shown in Supplemental Table 1. On average at baseline, men were 70.5 years of age (SD 8.8) with median PSA of $42.0 \mathrm{ng} / \mathrm{ml}$ (interquartile range (IQR) 16.1, 116.0). At baseline, $51 \%$ of men had metastatic disease in bone only, $17 \%$ in soft tissue only and $32 \%$ in both bone and soft tissue. The median percent change in PSA at 8 weeks after starting treatment was $-66.3 \%$ (IQR -88.0, -19.6) and $60 \%$ of subjects had a decline in PSA greater than $50 \%$.

Figure 1 shows the disposition of patients. A total of 301 of the 546 men experienced radiographic progression with a median time to event of 505 days (95\% confidence interval (CI) of 494 to 588). Over half (53\%) of the first events of progression were in bone, $44 \%$ were in soft tissue and $3 \%$ were in both bone and soft tissue.

The univariate associations for all covariates with time to radiographic progression are shown in Supplemental Table 1. The multivariable model including baseline variables only had a C-statistic of 0.67 (Supplemental Table 2). The final multivariable model included extent of disease at baseline, ECOG status, pain score, PSA, LDH, ALP and albumin, and change in PSA and ALP at 8 weeks $(\mathrm{C}$-statistic $=0.71)($ Table 1$)$.

Due to missing data, we did not include change in pain at 8 weeks in the modelling process. We added it to the final model (446 subjects and 250 events), but it was not significantly associated with radiographic progression $(p=0.23)$.

The association of baseline ALP with progression became stronger over time, while that of change in PSA become weaker ( $p=0.03$ and $p=0.05$, respectively, $)$. Adding interaction terms with time to the multivariable model increased the C-statistic only slightly (from 0.71 to 0.72 ) and they were not included in the final model. 
Figure 2 shows the Kaplan-Meier plots for tertiles of risk score calculated from the multivariable model in Table 1. Compared to the first tertile, the hazard ratios (HR) for the second and third tertiles were 2.01 (95\% CI 1.46, 2.77) and 3.43 (95\% CI 2.48, 4.74). respectively, and the C-statistic for the model was 0.63 . For patients in the first tertile of risk score (33\% of patients), the probability of RPFS at 6 months was 92\% (95\% CI 86, 95), while for those in the highest tertile (33\% of patients), the probability of RPFS was 70\% (95\% CI 61 to 77) (Table 2). The probability of RPFS ranged from $45 \%$ to $80 \%$ at 12 months.

Best subset regression identified two 2-variable models with a similar C-statistic (0.64). We show results for the model containing extent of baseline disease and percent change in PSA; however, qualitatively similar results were found when change in ALP was used instead of PSA (Supplemental Table 3). Figure 3 shows the Kaplan-Meier plots for subjects stratified into 6 groups based on these 2 variables. The survival curve for the lowest risk stratum (stratum 1; bone only disease at baseline and $\geq 50 \%$ decline in PSA) was significantly different from all other strata ( $\mathrm{P} \leq 0.0007$; log rank test, Tukey adjustment).

The survival curve for the highest risk stratum (Stratum 6: bone and soft tissue disease at baseline and $<50 \%$ decline in PSA) was significantly different from all other strata $(\mathrm{P}<0.02)$ except for the fifth stratum ( $\mathrm{p}=0.59)$. The HR comparing the highest to the lowest risk stratum was 4.17 (95\% CI 2.85, 6.10).

In the lowest risk stratum (32\% of subjects), the probability of RPFS at 6 months was 93\% (95\% CI 87, 96) and at 12 months was 80\% (95\% CI 72, 86) (Table 3). In contrast, the probability of RPFS for men in the highest risk stratum was 55\% (95\% CI 41 to 67) at 6 months and 34\% (95\% CI 22 to 47) at 12 months.

We applied the multivariable model developed for overall radiographic progression to bone progression only (Supplemental Table 4). The best 2-variable model (C-statistic $=0.67$ ) included baseline ALP and change in ALP and we stratified subjects by these variables (Table 4). The survival curve for the lowest risk stratum (baseline ALP below the median and $<20 \%$ increase in ALP) was significantly different from all other strata $(\mathrm{P} \leq 0.0003$, log rank test with Tukey adjustment); however, there were no significant differences between the other 3 strata ( $\mathrm{p}>0.16$ ). In the lowest risk stratum (35\% of subjects), the probability of RPFS at 6 months was 94\% (95\% CI 89, 97) and at 12 months was 88\% (95\% CI 81, 92). In contrast, the probability of RPFS in the other strata ranged from 73 to $88 \%$ at 6 months and from 52 to $75 \%$ at 12 months.

\section{Discussion}

Current guidelines for managing mCRPC do not provide recommendations regarding the frequency of imaging to monitor for radiographic progression. ${ }^{8,9}$ At a recent consensus conference, the majority of panelists (54\%) voted for regular imaging every 3-6 months for mCRPC patients on first-line therapy, while the remainder voted for imaging based on PSA levels and/or clinical progression. ${ }^{10}$ Our analysis shows that mCRPC patients on first line AA-P can be divided into groups with large differences in the probability of radiographic progression 
using only two clinically available factors. Importantly, the discriminant ability (C-statistic) for the 2-variable model (0.64) was almost identical to that with the risk score based on 9 covariates (0.63). These results suggest that risk-adapted imaging schedules could be developed for these patients.

As expected, several baseline factors that predict overall survival for mCRPC were also associated with radiographic progression in our multivariable analysis, including extent of disease, ${ }^{11}$ LDH, ${ }^{12-14}$ PSA, ${ }^{13,15}$ ALP, ${ }^{12-14,16}$ albumin, ${ }^{12,14,15}$ ECOG, ${ }^{12-15}$ and pain. ${ }^{13}$ To our knowledge there is only one published prognostic model for RPFS in the mCRPC setting. ${ }^{17}$ This model was developed in the same population as used here; however, there are differences in the two approaches. For the outcome of radiographic progression, Ryan et al ${ }^{17}$ used the results of independent radiographic review, whereas we had access to the investigator assessment only. Although, radiographic progression identified in these two ways showed a high degree of agreement overall $(79 \%)^{18}$, this difference could be responsible for the lower C-statistic we observed for the multivariate model with baseline variables only. However, because independent review was not done for the entire duration of the study, we were able to use a later clinical cutoff date (and larger number of events) by using the investigator assessment. In addition, in dayto-day practice imaging would not undergo central independent review and thus it is more pragmatic to use the investigator assessment.

Another important difference between these analyses is that Ryan et al ${ }^{17}$ included baseline variables only (lymph node disease, number of bone metastases, PSA, LDH and hemoglobin), whereas we included change in laboratory measurements as indicators of early treatment response. Changes in PSA and ALP at 8 weeks were strongly associated with overall and bone-specific progression. The PCWG3 criteria ${ }^{6}$ suggest that early changes (before 8 or 12 weeks) in PSA should be ignored in determining treatment response because of the potential for flare reactions and later responses. However, PSA flare may be uncommon following AA-P 19 and previous analyses have shown a strong association of early PSA changes with survival and radiographic progression. ${ }^{16,19-23}$ PSA declines of 30\%, 50\%, and 90\%, as well as more complex measures of PSA kinetics, are associated with survival and radiographic progression; ${ }^{20,22}$ however, it is not clear which measure has the best predictive ability.

In agreement with our results, change in serum ALP, a marker of bone metabolism, has been shown to be associated with survival ${ }^{24-26}$ and with bone progression specifically ${ }^{27,28}$ in mCRPC patients, independently of changes in PSA. Using baseline level and change in ALP, we identified a group of patients with low risk of bone progression ( $6 \%$ at 6 months) for whom the frequency of bone scans might be reduced.

Strengths of this work include a large sample size, high quality data collected as part of a clinical trial, and a standardized schedule of imaging. Because data on time to disease progression is highly dependent on the imaging schedule, imaging at standard intervals in all patients is necessary for this type of analysis. 
The generalizability of our results may be limited as the subjects were highly selected participants in a clinical trial who may be at different risk for progression than patients in the "real” world clinical setting. Our results may not apply to patients who present with visceral metastases at start of treatment or those who are treated with different drugs. In addition, our results apply to current standard imaging technologies and their associated sensitivity and specificity for detecting disease progression. Finally, our models have not been externally validated.

Information about the optimal schedule of imaging to monitor for radiographic progression is needed to inform clinical management of mCRPC. Our analyses suggest that mCRPC patients treated with first-line AA-P can be divided into groups with significantly different risks of experiencing radiographic progression based on a few clinically available variables. For example, patients with bone disease only at the start of treatment who experience an early decline of $\geq 50 \%$ in PSA compose a large group (about one-third of patients) with high probability of remaining progression free; only 1 in 5 patients in this group experienced progression by 1 year, and this may not represent clinically significant or symptomatic changes. In the absence of symptoms, imaging may be unnecessary for at least one year in these patients. In contrast, the highest risk group (15\% of patients with bone and soft tissue disease and $<50 \%$ decline in PSA) had a much lower probability of remaining progression free at 6 months (55\%) and may benefit from more earlier and/or more frequent imaging. Compared to an imaging schedule of every 3 months for all patients, if we imaged at 1 year only for the $30 \%$ of patients in the low risk stratum, we would expect an overall reduction of about $20 \%$ in imaging in the first year post treatment. These findings should be externally validated, and examined in other treatment settings, and may ultimately lead to more efficient imaging schedules and better care for mCRPC patients. 


\section{References}

1. Dinan MA, Curtis LH, Hammill BG, et al. Changes in the use and costs of diagnostic imaging among Medicare beneficiaries with cancer, 1999-2006. Jama 2010; 303: 162531.

2. Hu YY, Kwok AC, Jiang W, et al. High-cost imaging in elderly patients with stage IV cancer. J Natl Cancer Inst 2012; 104: 1164-72.

3. Accordino MK, Wright JD, Vasan S, et al. Use and costs of disease monitoring in women with metastatic breast cancer. J Clin Oncol 2016; 34: 2820-6.

4. Loprinzi CL, Hayes D, Smith T. Doc, shouldn't we be getting some tests? J Clin Oncol 2003; 21: 108s-11s.

5. Ryan CJ, Smith MR, de Bono JS, et al. Abiraterone in metastatic prostate cancer without previous chemotherapy. N Engl J Med 2013; 368: 138-48.

6. Scher HI, Halabi S, Tannock I, et al. Design and end points of clinical trials for patients with progressive prostate cancer and castrate levels of testosterone: recommendations of the Prostate Cancer Clinical Trials Working Group. J Clin Oncol 2008; 26: 1148-59.

7. Harrell FE, Jr., Lee KL, Mark DB. Multivariable prognostic models: issues in developing models, evaluating assumptions and adequacy, and measuring and reducing errors. Stat Med 1996; 15: 361-87.

8. Saad F, Chi KN, Finelli A, et al. The 2015 CUA-CUOG Guidelines for the management of castration-resistant prostate cancer (CRPC). Can Urol Assoc J 2015; 9: 90-6.

9. Basch E, Loblaw DA, Oliver TK, et al. Systemic therapy in men with metastatic castration-resistant prostate cancer:American Society of Clinical Oncology and Cancer Care Ontario clinical practice guideline. J Clin Oncol 2014; 32: 3436-48.

10. Gillessen S, Attard G, Beer TM, et al. Management of patients with advanced prostate cancer: The Report of the Advanced Prostate Cancer Consensus Conference APCCC 2017. Eur Urol 2017.

11. Halabi S, Kelly WK, Ma H, et al. Meta-Analysis evaluating the impact of site of metastasis on overall survival in men with castration-resistant prostate cancer. J Clin Oncol 2016; 34: 1652-9.

12. Chi KN, Kheoh T, Ryan CJ, et al. A prognostic index model for predicting overall survival in patients with metastatic castration-resistant prostate cancer treated with abiraterone acetate after docetaxel. Ann Oncol 2016; 27: 454-60.

13. Halabi S, Lin CY, Small EJ, et al. Prognostic model predicting metastatic castrationresistant prostate cancer survival in men treated with second-line chemotherapy. $J$ Natl Cancer Inst 2013; 105: 1729-37.

14. Khalaf DJ, Aviles CM, Azad AA, et al. A prognostic model for stratifying clinical outcomes in chemotherapy-naive metastatic castration-resistant prostate cancer patients treated with abiraterone acetate. Can Urol Assoc J 2018; 12: E47-e52. 
15. Halabi S, Lin CY, Kelly WK, et al. Updated prognostic model for predicting overall survival in first-line chemotherapy for patients with metastatic castration-resistant prostate cancer. J Clin Oncol 2014; 32: 671-7.

16. Pitcher B, Khoja L, Hamilton RJ, et al. Assessment of a prognostic model, PSA metrics and toxicities in metastatic castrate resistant prostate cancer using data from Project Data Sphere (PDS). PLoS One 2017; 12: e0170544.

17. Ryan CJ, Kheoh T, Li J, et al. Prognostic index model for progression-free survival in chemotherapy-naive metastatic castration-resistant prostate cancer treated with abiraterone acetate plus prednisone. Clin Genitourin Cancer 2018; 16: 72-77.

18. Morris MJ, Molina A, Small EJ, et al. Radiographic progression-free survival as a response biomarker in metastatic castration-resistant prostate cancer: COU-AA-302 results. J Clin Oncol 2015; 33: 1356-63.

19. Rescigno P, Lorente D, Bianchini D, et al. Prostate-specific antigen decline after 4 weeks of treatment with abiraterone acetate and overall survival in patients with metastatic castration-resistant prostate cancer. Eur Urol 2016; 70: 724-31.

20. Armstrong AJ, Saad F, Phung, et al. Clinical outcomes and survival surrogacy studies of prostate-specific antigen declines following enzalutamide in men with metastatic castration-resistant prostate cancer previously treated with docetaxel. Cancer 2017; 123 : 2303-11.

21. Bryce AH, Alumkal JJ, Armstrong A, et al. Radiographic progression with nonrising PSA in metastatic castration-resistant prostate cancer: post hoc analysis of PREVAIL. Prostate Cancer Prostatic Dis 2017; 20: 221-27.

22. Xu XS, Ryan CJ, Stuyckens K, et al. Correlation between prostate-specific antigen kinetics and overall survival in abiraterone acetate-treated castration-resistant prostate cancer patients. Clin Cancer Res 2015; 21: 3170-7.

23. Fuerea A, Baciarello G, Patrikidou A, et al. Early PSA response is an independent prognostic factor in patients with metastatic castration-resistant prostate cancer treated with next-generation androgen pathway inhibitors. Eur J Cancer 2016; 61: 44-51.

24. Cook RJ, Coleman R, Brown J, et al. Markers of bone metabolism and survival in men with hormone-refractory metastatic prostate cancer. Clin Cancer Res 2006; 12: 3361-7.

25. Sonpavde G, Pond GR, Berry WR, et al. Serum alkaline phosphatase changes predict survival independent of PSA changes in men with castration-resistant prostate cancer and bone metastasis receiving chemotherapy. Urol Oncol 2012; 30: 607-13.

26. Som A, Tu SM, Liu J, et al. Response in bone turnover markers during therapy predicts overall survival in patients with metastatic prostate cancer: analysis of three clinical trials. Br J Cancer 2012; 107: 1547-53.

27. Lein M, Wirth M, Miller K, et al. Serial markers of bone turnover in men with metastatic prostate cancer treated with zoledronic Acid for detection of bone metastases progression. Eur Urol 2007; 52: 1381-7. 
28. Hammerich KH, Donahue TF, Rosner IL, et al. Alkaline phosphatase velocity predicts overall survival and bone metastasis in patients with castration-resistant prostate cancer. Urol Oncol 2017; 35: 460.e21-60.e28. 


\section{Figures and Tables}

Fig. 1. Disposition of patients and dataset for analysis.

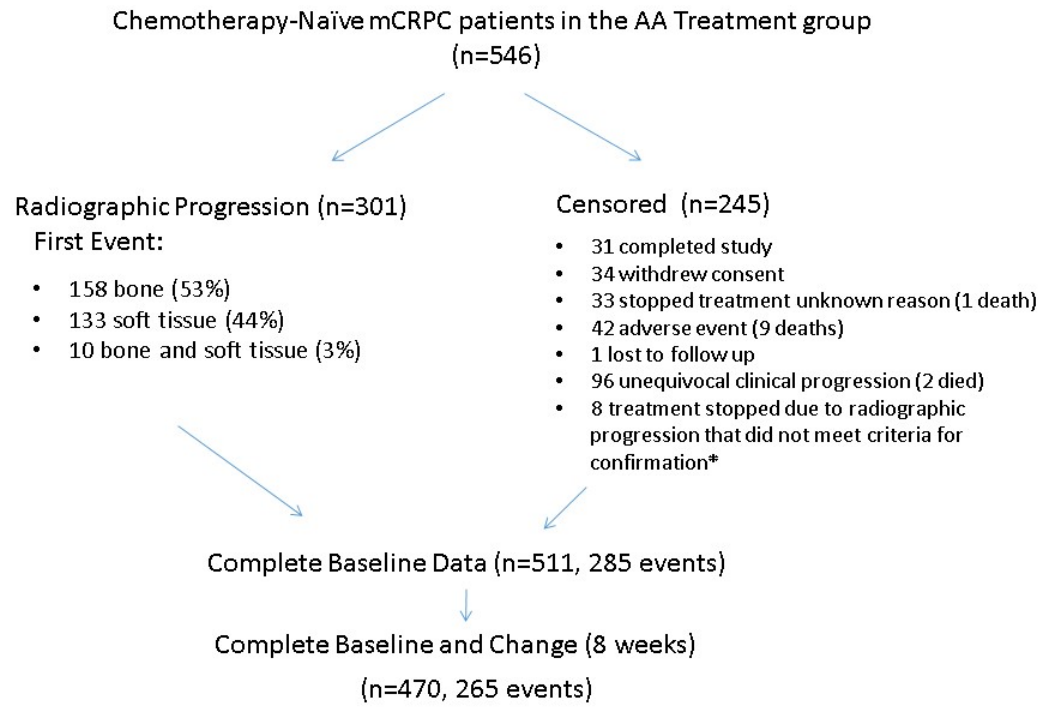

\footnotetext{
* 3 new bone lesions (no confirmatory scan); 2 for which confirmatory scans $<42$ days after previous scan;
} and 3 no evidence of bone lesion at any visit

Fig. 2. Kaplan-Meier curves showing radiographic progression-free survival by tertiles of risk score. The risk score was calculated for each subject by multiplying their covariate values by the appropriate regression coefficient from the final multivariable model (Table 2). Subjects were divided into tertiles based on their risk score.

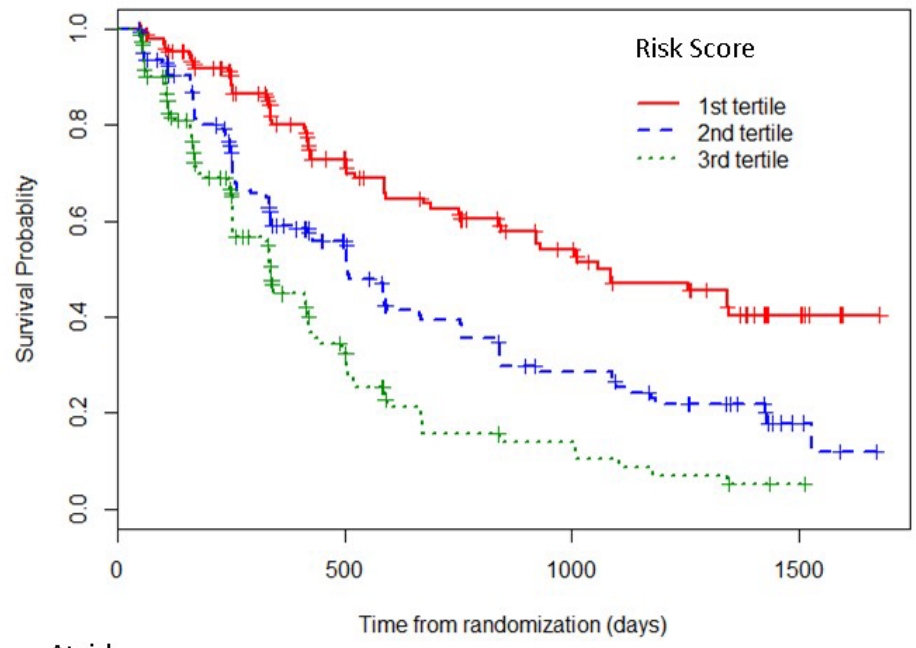

At risk

Tertile $\begin{array}{cc}1 & 155 \\ 2 & 160\end{array}$

$\begin{array}{ll}2 & 160 \\ 3 & 155\end{array}$

74

64
30

41
27
8

11
4
1 
Fig. 3. Kaplan-Meier curves showing radiographic progression-free survival for patients stratified by extent of baseline disease and the percent change in prostate-specific antigen (PSA) at 8 weeks. Stratum 1=bone only disease at baseline and $\geq 50 \%$ decline in PSA; stratum 2=bone only disease at baseline and $<50 \%$ decline in PSA; stratum $3=$ soft only disease at baseline and $\geq 50 \%$ decline in PSA; stratum $4=$ soft only disease at baseline and $<50 \%$ decline in PSA; stratum $5=$ bone and soft disease at baseline and $\geq 50 \%$ decline in PSA; stratum $6=$ bone and soft disease at baseline and $<50 \%$ decline in PSA.
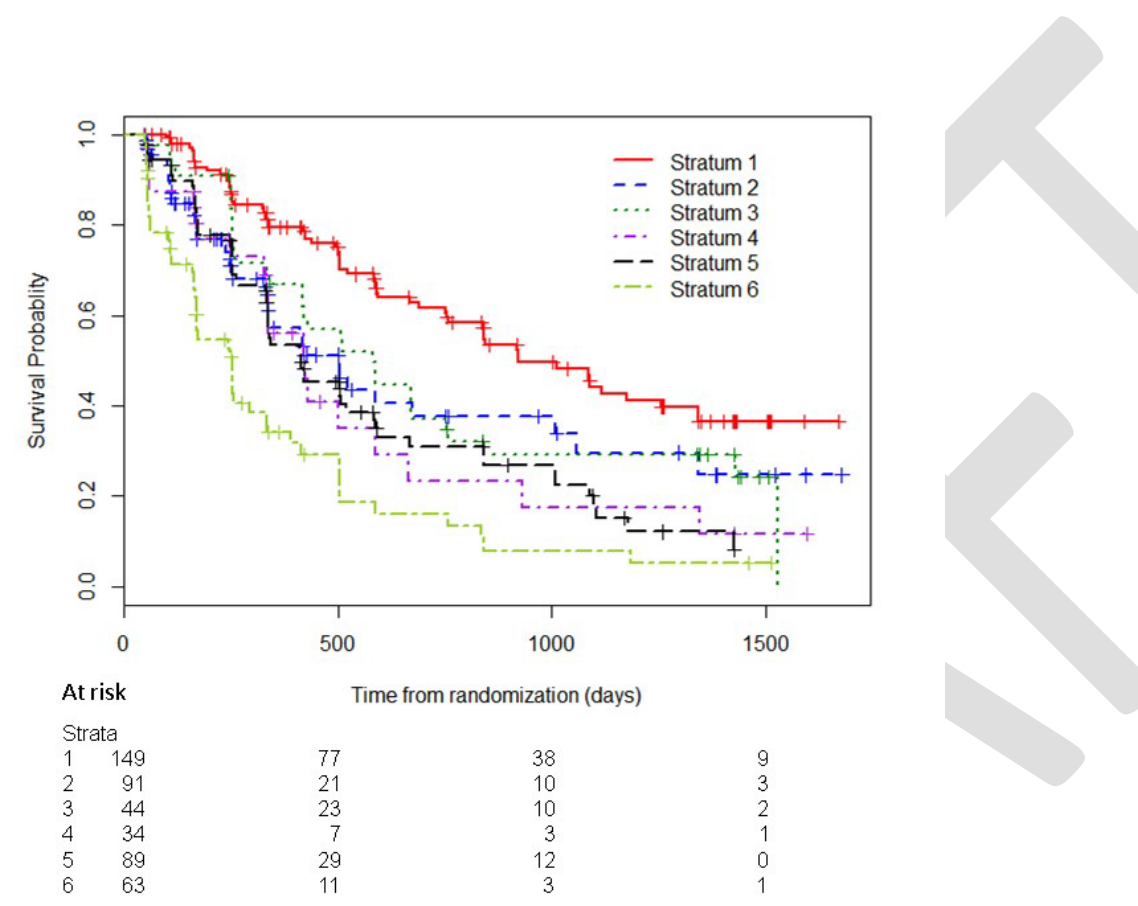


\begin{tabular}{|c|c|c|c|}
\hline Variable & n (\%) or mean (SD) & HR (95\% CI) & $\mathbf{p}$ \\
\hline $\begin{array}{l}\text { Extent of disease at baseline } \\
\text { Bone only } \\
\text { Soft only } \\
\text { Bone and soft }\end{array}$ & $\begin{array}{l}240(51) \\
78(17) \\
152(32) \\
\end{array}$ & $\begin{array}{c}1.0 \\
1.53(1.08,2.17) \\
1.99(1.51,2.62) \\
\end{array}$ & $\begin{array}{c}0.02 \\
0.0001 \\
\end{array}$ \\
\hline $\begin{array}{c}\text { ECOG } \\
0 \\
1 \\
\end{array}$ & $\begin{array}{l}360(77) \\
110(23) \\
\end{array}$ & $\begin{array}{c}1.0 \\
0.72(0.52,1.00) \\
\end{array}$ & 0.05 \\
\hline $\begin{array}{l}\text { Pain (Item 3) } \\
0 \\
1-2 \\
\geq 3\end{array}$ & $\begin{array}{c}240(51) \\
152(32) \\
78(17) \\
\end{array}$ & $\begin{array}{c}1.0 \\
1.23(0.93,1.64) \\
1.70(1.20,2.40)\end{array}$ & $\begin{array}{c}0.15 \\
0.003\end{array}$ \\
\hline PSA (log ng/ml) & $3.72(1.52)$ & $1.13(1.03,1.23)$ & 0.009 \\
\hline $\begin{array}{l}\text { LDH (IU/L) } \\
\text { “Normal” } \\
\text { High }(\geq 250)\end{array}$ & $\begin{array}{c}417(89) \\
53(11) \\
\end{array}$ & $\begin{array}{c}1.0 \\
1.48(0.98,2.23)\end{array}$ & 0.07 \\
\hline $\begin{array}{l}\text { ALP }(\log \text { IU/L) } \\
\text { Albumin }(g / L)\end{array}$ & $\begin{array}{c}4.67(0.61) \\
40.4(3.3) \\
\end{array}$ & $\begin{array}{l}1.33(1.05,1.68) \\
0.97(0.93,1.01) \\
\end{array}$ & $\begin{array}{l}0.02 \\
0.12 \\
\end{array}$ \\
\hline Change at 8 weeks & & 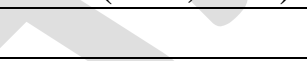 & \\
\hline $\begin{array}{l}\text { PSA } \\
\quad<50 \% \text { drop } \\
\geq 50 \% \text { drop } \\
\end{array}$ & $\begin{array}{l}282(60) \\
188(40) \\
\end{array}$ & $\begin{array}{c}1.0 \\
0.59(0.46,0.76) \\
\end{array}$ & $<0.0001$ \\
\hline $\begin{array}{l}\text { ALP } \\
\quad<20 \% \text { increase } \\
\quad \geq 20 \% \text { increase }\end{array}$ & $\begin{array}{l}355(76) \\
115(24)\end{array}$ & $\begin{array}{c}1.0 \\
1.64(1.22,2.20) \\
\end{array}$ & 0.001 \\
\hline
\end{tabular}

ALP: alkaline phosphatase; ECOG: Eastern Cooperative Oncology Group performance status; HR: hazard ratio; LDH: lactate dehydrogenase; PSA: prostate-specific antigen; SD: standard deviation. 


\begin{tabular}{|l|l|c|c|c|c|}
\hline $\begin{array}{l}\text { Table 2. Probability of radiographic progression-free survival by tertiles of risk score } \\
\text { (n=470 subjects, } 265 \text { events) }\end{array}$ \\
\hline $\begin{array}{l}\text { Score } \\
\text { tertile }\end{array}$ & n (\%) & $\begin{array}{c}\text { \# of } \\
\text { events }\end{array}$ & $\begin{array}{c}\text { Median time to } \\
\text { event (days) } \\
\text { (95\% CI) }\end{array}$ & $\begin{array}{c}\text { 6-month RPFS } \\
\text { probability } \\
\text { (95\% CI) }\end{array}$ & $\begin{array}{c}\text { 1-year RPFS } \\
\text { probability } \\
\text { (95\% CI) }\end{array}$ \\
\hline 1 & $155(33)$ & 61 & $1057(839$, ND) & $92(86,95)$ & $80(72,86)$ \\
\hline 2 & $160(34)$ & 101 & $505(389,593)$ & $80(73,86)$ & $59(51,67)$ \\
\hline 3 & $155(33)$ & 103 & $337(254,415)$ & $70(61,77)$ & $45(36,53)$ \\
\hline
\end{tabular}

CI: confidence intervals; ND: not determined; RPFS: radiographic progression-free survival.

\begin{tabular}{|c|c|c|c|c|c|c|c|}
\hline & Covariate & lues & & & $x_{2}$ & & \\
\hline $\begin{array}{l}\text { Risk } \\
\text { strata }\end{array}$ & $\begin{array}{l}\text { Extent of } \\
\text { baseline } \\
\text { disease }\end{array}$ & $\begin{array}{c}\text { Fall in PSA } \\
\text { at } 8 \text { weeks }\end{array}$ & n (\%) & \# events & $\begin{array}{l}\text { Median time to } \\
\text { event (days) } \\
\text { (95\% CI) }\end{array}$ & $\begin{array}{l}\text { 6-month } \\
\text { RPFS } \\
(95 \% \text { CI) }\end{array}$ & $\begin{array}{l}\text { 12-month } \\
\text { RPFS } \\
(95 \% \text { CI })\end{array}$ \\
\hline 1 & Bone only & $\geq 50 \%$ & $149(32)$ & 64 & $921(754,1255)$ & $93(87,96)$ & $80(72,86)$ \\
\hline 2 & Bone only & $<50 \%$ & 91 (19) & 42 & $503(336,1008)$ & $77(66,85)$ & $57(44,68)$ \\
\hline 3 & Soft only & $\geq 50 \%$ & $44(9)$ & 31 & $582(418,754)$ & $91(77,96)$ & $67(51,79)$ \\
\hline 4 & Soft only & $<50 \%$ & $34(7)$ & 20 & $424(328,588)$ & $77(57,88)$ & $56(35,73)$ \\
\hline 5 & Bone and soft & $\geq 50 \%$ & 89 (19) & 61 & $414(337,518)$ & $78(67,85)$ & $54(42,64)$ \\
\hline 6 & Bone and soft & $<50 \%$ & $63(13)$ & 47 & $252(168,332)$ & $55(41,67)$ & $34(22,47)$ \\
\hline
\end{tabular}

CI: confidence intervals; PSA: prostate-specific antigen; RPFS: radiographic progression-free survival. 


\begin{tabular}{|c|c|c|c|c|c|c|c|}
\hline & Covariate & values & & & & & \\
\hline $\begin{array}{l}\text { Risk } \\
\text { strata }\end{array}$ & Baseline ALP & $\begin{array}{c}\text { Increase in } \\
\text { ALP at } 8 \\
\text { weeks }\end{array}$ & n (\%) & $\begin{array}{c}\# \\
\text { events }\end{array}$ & $\begin{array}{l}\text { Median time to } \\
\text { event (days) } \\
(95 \% \text { CI })\end{array}$ & $\begin{array}{l}\text { 6-month } \\
\text { RPFS (95\% } \\
\text { CI) }\end{array}$ & $\begin{array}{l}\text { 12-month } \\
\text { RPFS } \\
\text { (95\% CI) }\end{array}$ \\
\hline 1 & Below median $^{\mathrm{b}}$ & $<20 \%$ & $164(35)$ & 32 & ND & $94(89,97)$ & $88(81,92)$ \\
\hline 2 & Below median & $\geq 20 \%$ & $45(10)$ & 18 & $593(244, \mathrm{ND})$ & $73(55,84)$ & $55(37,70)$ \\
\hline 3 & Above median & $<20 \%$ & $191(41)$ & 71 & $841(588,1174)$ & $88(82,92)$ & $75(68,81)$ \\
\hline 4 & Above median & $\geq 20 \%$ & $70(15)$ & 28 & $421(252,494)$ & $74(60,83)$ & $52(36,67)$ \\
\hline
\end{tabular}

${ }^{\mathrm{a}}$ Events of soft tissue progression censored; ${ }^{\mathrm{b}}$ median ALP=93.0 IU/L. ALP: alkaline phosphatase; CI: confidence interval; ND: not determined; RPFS: radiographic progression-free survival. 


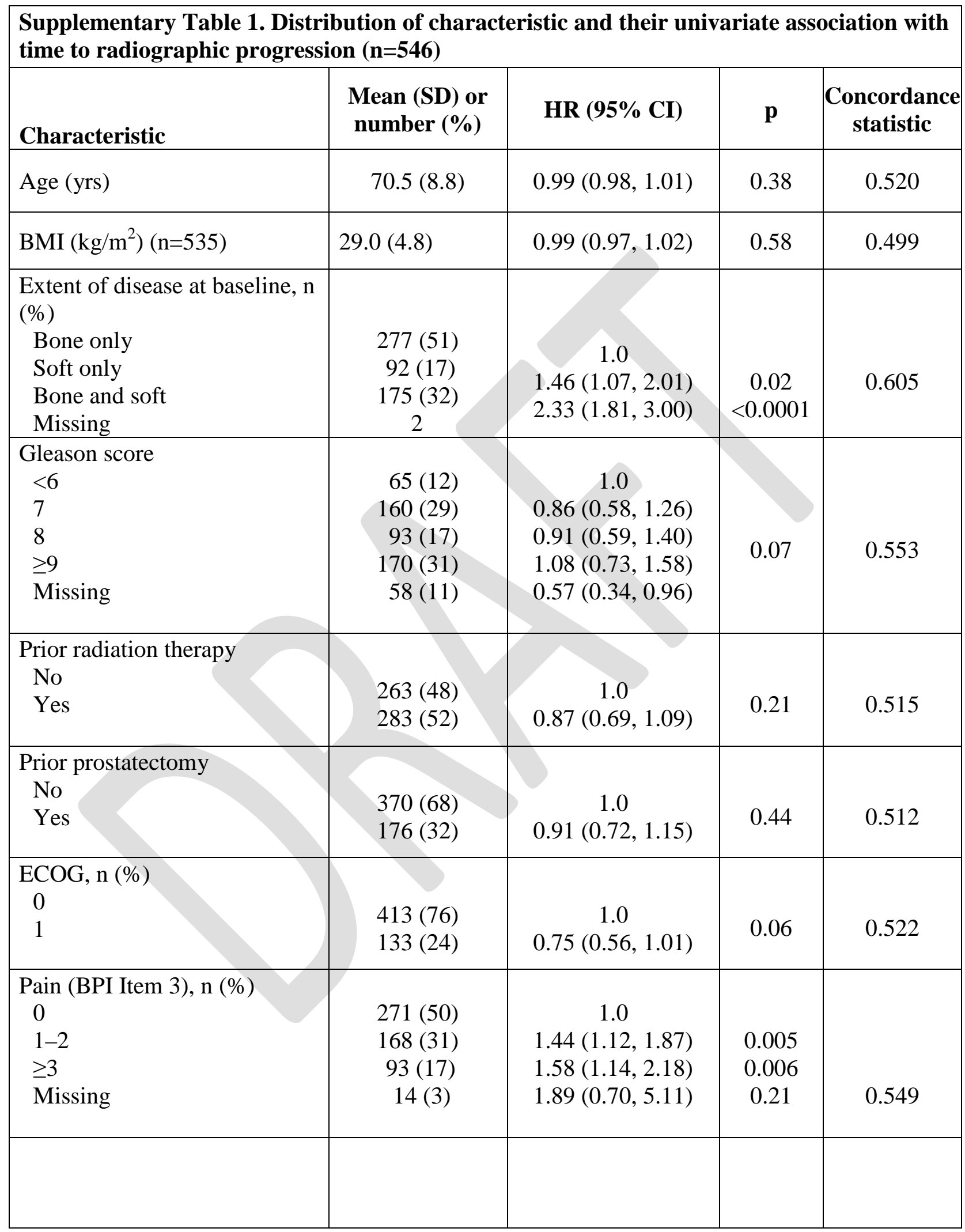




\begin{tabular}{|c|c|c|c|c|}
\hline $\begin{array}{l}\text { PSA (ng/ml) } \\
\text { Median (IQR) } \\
\text { Log PSA }\end{array}$ & $\begin{array}{l}42.0(100) \\
3.76(1.53)\end{array}$ & $1.22(1.13,1.31)$ & $<0.0001$ & 0.593 \\
\hline $\begin{array}{l}\text { Lactate dehydrogenase (U/L) } \\
\text { Normal } \\
\text { High }(\geq 250 \mathrm{IU} / \mathrm{L}) \\
\text { Missing }\end{array}$ & $\begin{array}{c}487(89) \\
56(10) \\
3(1)\end{array}$ & $\begin{array}{c}1.0 \\
1.99(1.38,2.87)\end{array}$ & 0.0002 & 0.540 \\
\hline $\begin{array}{l}\text { Alkaline phosphatase (IU/L) } \\
\text { Median (IQR) } \\
\text { Log ALP }\end{array}$ & $\begin{array}{c}93.0(66) \\
4.66(0.61)\end{array}$ & $1.49(1.24,1.78)$ & $<0.0001$ & 0.571 \\
\hline $\begin{array}{l}\text { Albumin }(\mathrm{g} / \mathrm{L}) \\
(\mathrm{n}=539)\end{array}$ & $40.4(3.2)$ & $0.95(0.92,0.99)$ & 0.01 & 0.546 \\
\hline $\begin{array}{l}\text { Hemoglobin }(\mathrm{g} / \mathrm{dl}) \\
(\mathrm{n}=544)\end{array}$ & $129.7(12.2)$ & $0.99(0.98,1.00)$ & 0.02 & 0.557 \\
\hline $\begin{array}{l}\text { Percent change in PSA at } 8 \\
\text { weeks, } \mathrm{n}(\%), \mathrm{n}=507 \\
<50 \% \text { decrease } \\
\geq 50 \% \text { decrease }\end{array}$ & $\begin{array}{l}203(40) \\
304(60)\end{array}$ & $\begin{array}{c}1.0 \\
0.54(0.42,0.69)\end{array}$ & $<0.0001$ & 0.593 \\
\hline $\begin{array}{l}\text { Mean (SD) } \\
\text { Median (IQR) }\end{array}$ & $\begin{array}{l}-44.1(61.4) \\
-66.3(68.4)\end{array}$ & $1.01(1.00,1.01)$ & 0.0001 & 0.628 \\
\hline $\begin{array}{l}\text { Percent change in ALP at } 8 \\
\text { weeks (n,\%), } n=537 \\
<20 \% \text { increase } \\
\geq 20 \% \text { increase }\end{array}$ & $\begin{array}{l}404(75) \\
133(25)\end{array}$ & $\begin{array}{c}1.0 \\
2.10(1.62,2.72)\end{array}$ & $<0.0001$ & 0.581 \\
\hline $\begin{array}{l}\text { Mean (SD) } \\
\text { Median (IQR) }\end{array}$ & $\begin{array}{c}11.5(51.7) \\
1.5(8)\end{array}$ & $1.01(1.00,1.01)$ & $<0.0001$ & 0.593 \\
\hline $\begin{array}{l}\text { Percent change in LDH, } \\
\mathrm{n}=531\end{array}$ & $7.7(26.4)$ & $1.00(0.99,1.01)$ & 0.80 & 0.545 \\
\hline $\begin{array}{l}\text { Change in albumin, } \\
\mathrm{n}=523\end{array}$ & $-2.4(7.9)$ & $1.02(1.00,1.03)$ & 0.07 & 0.531 \\
\hline $\begin{array}{l}\text { Change in hemoglobin, } \\
\mathrm{n}=523\end{array}$ & $2.3(6.8)$ & $1.04(1.02,1.05)$ & 0.0001 & 0.552 \\
\hline
\end{tabular}

ALP: alkaline phosphatase; BMI: body mass index; BPI: Brief Pain Inventory; CI: confidence interval; ECOG: Eastern Cooperative Oncology Group Performance status; HR: hazard ratio; IQR: interquartile range; LDH: lactate dehydrogenase; PSA: prostate specific antigen; SD: standard deviation. 


\begin{tabular}{|c|c|c|}
\hline \multicolumn{3}{|c|}{$\begin{array}{l}\text { Supplementary Table } 2 \text {. Baseline multivariable Cox proportional hazards model } \\
\text { (n=511 subjects, } 284 \text { events) (C-statistic }=0.67) \text {. }\end{array}$} \\
\hline Variable & HR (95\% CI) & $\mathbf{p}$ \\
\hline \multicolumn{3}{|l|}{$\begin{array}{l}\text { Extent of disease } \\
\text { at baseline }\end{array}$} \\
\hline Bone only & 1.0 & \\
\hline Soft only & $1.55(1.10,2.19)$ & 0.01 \\
\hline Bone and soft & $2.08(1.60,2.71)$ & $<0.0001$ \\
\hline \multicolumn{3}{|l|}{ ECOG } \\
\hline 0 & 1.0 & 0.03 \\
\hline 1 & $0.71(0.52,0.97)$ & \\
\hline \multicolumn{3}{|l|}{ Pain (Item 3) } \\
\hline 0 & 1.0 & \\
\hline $1-2$ & $1.20(0.92,1.58)$ & 0.18 \\
\hline$\geq 3$ & $1.70(1.22,2.38)$ & 0.002 \\
\hline \multicolumn{3}{|c|}{ Laboratory measures } \\
\hline PSA (log) & $1.15(1.05,1.25)$ & 0.002 \\
\hline LDH & & \\
\hline Normal & 1.0 & 0.02 \\
\hline High $(\geq 250)$ & $1.64(1.09,2.48)$ & \\
\hline ALP $(\log )$ & $1.25(1.00,1.56)$ & 0.05 \\
\hline Albumin & $0.96(0.92,0.99)$ & 0.02 \\
\hline
\end{tabular}

ALP: alkaline phosphatase; CI: confidence interval; ECOG: Eastern Cooperative Oncology Group; HR: hazard ratio; LDH: lactate dehydrogenase; PSA: prostate-specific antigen. 


\begin{tabular}{|c|c|c|c|c|c|c|c|}
\hline \multicolumn{8}{|c|}{$\begin{array}{l}\text { Supplementary Table } 3 \text {. Probability of radiographic progression-free survival by risk strata using } \\
\text { change in ALP instead of change in PSA (n=470 subjects, } 265 \text { events) }\end{array}$} \\
\hline \multirow[b]{2}{*}{$\begin{array}{l}\text { Risk } \\
\text { group }\end{array}$} & \multicolumn{2}{|c|}{ Covariate Values } & \multirow[b]{2}{*}{$\begin{array}{l}\text { \# total/ } \\
\text { events }\end{array}$} & \multirow[b]{2}{*}{$\begin{array}{c}\% \\
\text { subjects }\end{array}$} & \multirow[b]{2}{*}{$\begin{array}{c}\text { Median RPFS } \\
\text { (days) } \\
\text { (95\% CI) }\end{array}$} & \multirow[b]{2}{*}{$\begin{array}{c}\text { 6-month } \\
\text { RPFS } \\
(95 \% \text { CI) }\end{array}$} & \multirow[b]{2}{*}{$\begin{array}{l}\text { 12-month } \\
\text { RPFS } \\
\text { (95\% CI) }\end{array}$} \\
\hline & $\begin{array}{c}\text { Extent of } \\
\text { baseline } \\
\text { disease }\end{array}$ & $\begin{array}{c}\text { Fall in } \\
\text { ALP at C3 }\end{array}$ & & & & & \\
\hline 1 & Bone only & $<20 \%$ & 178/74 & 38 & $1057(839,1342)$ & $91(85,94)$ & $79(72,85)$ \\
\hline 2 & Bone only & $\geq 20 \%$ & $62 / 32$ & 13 & $336(247,494)$ & $75(60,85)$ & $43(27,57)$ \\
\hline 3 & Soft only & $<20 \%$ & 60/39 & 13 & $511(341,672)$ & $90(78,95)$ & $63(49,75)$ \\
\hline 4 & Soft only & $\geq 20 \%$ & $18 / 12$ & 4 & $500(58,670)$ & $69(41,86)$ & $62(34,81)$ \\
\hline 5 & $\begin{array}{c}\text { Bone and } \\
\text { soft }\end{array}$ & $<20 \%$ & $117 / 83$ & 25 & $410(332,504)$ & $76(66,83)$ & $51(41,60)$ \\
\hline 6 & $\begin{array}{c}\text { Bone and } \\
\text { soft }\end{array}$ & $\geq 20 \%$ & $35 / 25$ & 7 & $169(61,338)$ & $44(27,61)$ & $26(11,44)$ \\
\hline
\end{tabular}

ALP: alkaline phosphatase; CI: confidence intervals; PSA: prostate-specific antigen; RPFS:

radiographic progression-free survival. 


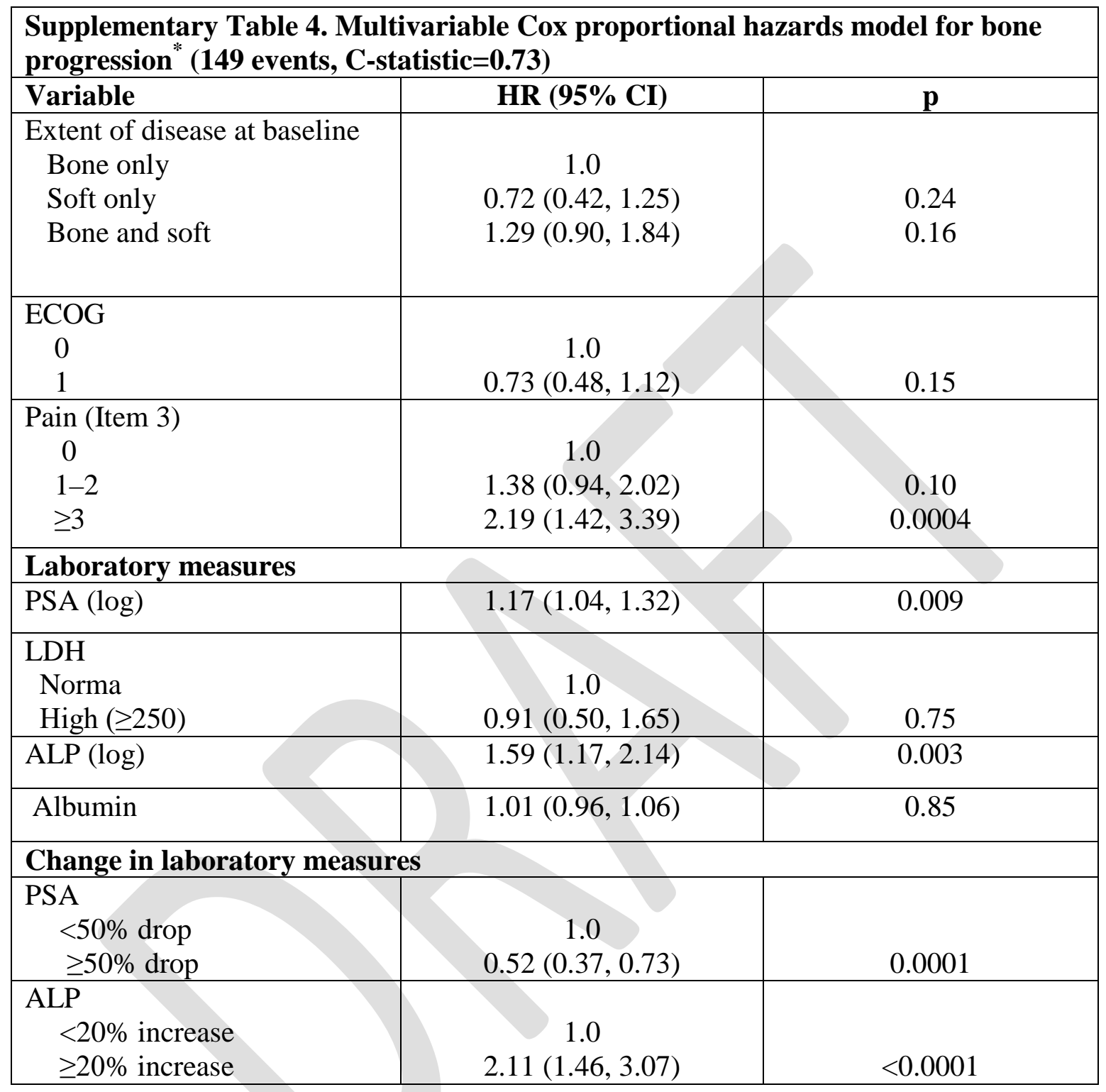

*Bone=bone only AND bone and soft $(\mathrm{n}=10)$ based on first event. ALP: alkaline phosphatase; CI: confidence interval; ECOG: Eastern Cooperative Oncology Group; LDH: lactate dehydrogenase; PSA: prostate-specific antigen. 